\title{
Measles Outbreak Investigation in Guradamole District of Bale Zone, South Eastern Ethiopia, 2021
}

\author{
Geremew Tsegaye $\mathbb{D}^{\prime}$, Yenealem Gezahegn², Assegid Tesfaye', Gadissa Mulatu², \\ Gemechu Gudina Bulcha ${ }^{4}$, Naod Berhanu ${ }^{5}$ \\ 'Ethiopian Field Epidemiology and Laboratory Training Program, Faculty of Public Health, Jimma University, Jimma, Ethiopia; ${ }^{2}$ Department of \\ Epidemiology, Faculty of Public Health, Jimma University, Jimma, Ethiopia; ${ }^{3}$ Disease Control and Prevention Department, Bale Zone Health Office, \\ Robe, Ethiopia; ${ }^{4}$ Public Health Emergency Management Department, Oromia Regional Health Bureau, Addis Ababa, Ethiopia; ${ }^{5}$ Field Epidemiology, \\ Department of Epidemiology, Faculty of Public Health, Jimma University, Jimma, Ethiopia
}

Correspondence: Geremew Tsegaye, Ethiopian Field Epidemiology and Laboratory Training Program, Faculty of Public Health, Jimma University, Jimma, Ethiopia, Email garamuts0606@gmail.com

Background: Measles is a highly contagious viral illness and globally, 142,300 people died from measles in 2018. On 25 March 2021, an outbreak of measles was reported from Guradamole district Bale Zone Southeast Ethiopia. Hence, we investigated to determine existence of the outbreak and to identify the associated factors.

Method: Descriptive and 1:2 unmatched case-control study was done in Guradamole district from March 25 to April 9/2021. For the descriptive study, a total of 98 cases were used. To identify the factor associated with the outbreak, 60 cases were selected by computer-generated simple random method by using line list as a sampling frame and 120 controls were studied. Active cases were identified through home-to-home searching in affected kebeles and controls were selected from neighbors of cases. Five serum samples were taken and an IgM test was done to confirm cases. Cases were any person who developed fever, maculopapular rash and cough, coryza or conjunctivitis while controls were without such diagnosis. We collected data by using a structured questionnaire, cases were described by time, place, and person; logistic regression was used to identify factors associated with measles. In the multivariable analysis $P$-value $<0.05$ was declared statistical significance.

Results: Overall, 98 cases were identified with an overall attack rate of $12 / 1000$ population and a case fatality rate (CFR) of $7 \%$. The highest attack rate (38/1000 population) and CFR (57\%) were among children aged $<59$ months. Vaccination efficacy was calculated to be $82.6 \%$. Being unvaccinated (adjusted odds ratio/AOR $=5.66,95 \%$ confidence interval, $\mathrm{CI}$ : $1.24-25.81$ ), contact with patient $(\mathrm{AOR}=3.24,95 \% \mathrm{CI}$ : 1.03-10.17), moderate malnutrition ( $\mathrm{AOR}=4.34,95 \% \mathrm{CI}: 2.14-8.814$ ), distance from health facility ( $\mathrm{AOR}=4.58,95 \% \mathrm{CI}$ : $1.39-15.19$ ) and history of travel to affected area $(\mathrm{AOR}=3.99,95 \% \mathrm{CI}$ : $1.31-12.19)$ were shown significant associated with measles infection.

Conclusion: The attack and fatality rate of the investigation were high. Being unvaccinated, distant from the health facility, malnutrition, and history of contact with measles case were associated with the outbreak. We recommend conducting vaccination campaigns, interventions to malnutrition, and strengthening routine immunization programs to reduce future measles outbreaks.

Keywords: measles, outbreak, Guradamole, Bale, Ethiopia

\section{Background}

Measles is a highly transmissible viral disease occurring as a result of paramyxovirus virus infection, which results in a fever, rash, and conjunctivitis and also leads to blindness, encephalitis or even death. ${ }^{1}$ Transmission is basically airborne and through close contact with secretions of an infected person. Patients are contagious about four days before and after rash eruption. ${ }^{2}$ In nonimmune subjects secondary infection reaches up to 18 persons compared to the immune ones. $^{3}$ In endemic areas measles outbreak reoccurs during the dry season. Incidence reaches climax level during late winter and early spring in tropical and temperate zones. ${ }^{2}$

According to the World Health Organization (WHO) and partners, all six WHO regions encountered measles in 2019. As a result of COVID-19 emergency measles immunization, surveillance and supplementary immunization campaigns were halted and a significant step back in progress toward global measles elimination was reported in $2019 .{ }^{4}$ 
To prevent measles, a country has to achieve and sustain 95\% coverage of measles vaccine (MCV1 and 2), but MCV1 vaccination rates have stalled at $81 \%$ and second dose stands at just $54 \%$ in Ethiopia and other Global Alliance for Vaccine and Immunization (GAVI)-supported countries. ${ }^{5}$ Globally in $2017,85 \%$ and $67 \%$ of the children had received MCV1 and 2, respectively, which resulted in averting 110,000 deaths from measles. MCV2 was included in routine national immunization by 167 countries. ${ }^{1}$ Although Ethiopia is working toward elimination of measles incidence is still greater than 50/1,000,000 population per year.,

In the presence of large numbers of unvaccinated persons, the measles virus can cause a widespread outbreak, despite the availability of safe and effective measles-containing vaccines. ${ }^{7}$ As of November 5, 2019, measles continues in many parts of the world as an outbreak of 440,263 confirmed cases are reported to the World Health Organization (WHO) by 187 countries in $2019 .^{7}$ In 2019, measles increased by more than twofold (120\%) and 10-fold in Europe and Africa, respectively. ${ }^{8}$

The burden of measles occurred disproportionally in infants under one year of age. ${ }^{8}$ In developing countries, an estimated 100,000 measles related death continue to occur each year until 2030. Despite availability of measles vaccination in many countries, measles continues to present threats to both unvaccinated and incompletely vaccinated individuals, which affects individual and population health and increase financial costs. ${ }^{9}$

In African countries measles remain a priority health problem and remains among one of the top causes of death in under five-year-old children. According to WHO report, measles caused an estimated 40,000 deaths annually in the African region in $2013 .{ }^{10}$ As of November 17, 2019, in Africa about 250,270 suspected cases with 5110 related deaths have been reported, an increase of 8000 cases compared to the same period of the previous year. $^{7}$

Despite the introduction of the lifesaving vaccines, vaccine-preventable diseases (VPDs) including measles still accounts for the death of more than half a million children under five years olds every year in Africa - representing 56\% of global VPD-related deaths. ${ }^{11}$ The region failed to reach national coverage targets for MCV1 of 95\%. Nigeria, Ethiopia, and the Democratic Republic of Congo (DRC) are among the homes of 50\% of the children not receiving MCV1. ${ }^{11}$

According to Ethiopian demographic health survey 2019, in Ethiopia only 55\% of children were vaccinated with a measles containing vaccination one (MCV1) and $9 \%$ of children aged 24-35 months received MCV2. ${ }^{12}$

The risk of developing severe measles increases in children aged less than five years, and individuals living in overcrowded areas, those who are malnourished having vitamin A deficiency, depending on predisposing conditions and age, measles complications occur in about $30 \%$ of cases. In districts where malnutrition like vitamin A deficiency, and exposure to other infectious diseases are common, the measles case fatality rate is $3-6 \%$, but can reach $30 \%$, especially among isolated people. ${ }^{2,13}$

According to the Ethiopian Demographic and Health Survey 2019 in Ethiopia national measles vaccination coverage is $59 \%$ and $9 \%$ for MCV1 and MCV2 respectively, which is lower than the WHO standard of $95 \%$ vaccination coverage. $^{12,14}$ Due to such a low vaccination coverage and poor living conditions, outbreaks of measles frequently explode in many parts of the country. ${ }^{13}$.

Previous studies conducted on measles outbreaks showed that the possible risk factors of measles outbreaks were, low measles vaccination coverage, nutritional problem, vitamin A deficiency, low socioeconomic living conditions, absence of vaccination facilities in remote areas and being pastoralist, travel history, contact history, and unaware of the need of immunization and lower levels of education were associated with measles outbreaks. ${ }^{15,16,20-30}$

To confirm suspected cases, laboratory diagnosis is very important for measles-specific IgM detection and to identify the genotype. ${ }^{17}$ Timely and thorough case investigation should, confirm the patient's diagnosis, ensure appropriate medical follow-up for affected persons, identify the source of infection, locate persons who may have been exposed, and isolate potentially infectious persons to prevent transmission of illness in the community. ${ }^{17}$

Outbreak investigation provides an opportunity to identify at-risk groups, changes in measles epidemiology, and gaps in the routine immunization program. ${ }^{18}$ Outbreak investigations can help to identify the source of measles, characterize by person, place, and time and guide public health intervention. ${ }^{19}$ Hence the aim of this investigation is to determine the existence of the outbreak and to identify the factors related with the measles outbreak in Guradamole district, Bale Zone, Oromia region Southeast Ethiopia, 2021. 


\section{Methods and Materials}

\section{Study Area}

The investigation was conducted in Guradamole Woreda of Bale Zone, Southeast Ethiopia. Guradamole is $130 \mathrm{~km}$ from Robe city capital of Bale Zone. The total population projected for 2020/2021 is 41,323 of which 20,456 (49.5\%) were females and 20,868 (50.5) were males. Of the total population 19,169 (46.3\%) were children under five and 2360 (5.7\%) were under two years. The district has a total of 8625 households with 4.8 family sizes. About 8718 (21\%) of the population were pastoralists. Administrative immunization coverage of measles containing vaccine (MCV) of the district in 2020 is $75 \%$.

\section{Study Design}

A cross sectional and unmatched 1:2 case-control study design was conducted.

\section{Study Period}

The investigation was conducted starting from February 20, 2021 to May 22, 2021.

\section{Source Population}

All population in the five affected kebeles was considered as the source population.

\section{Study Population - Case}

Any person in Guradamole, who developed fever, maculopapular rash and/or cough, coryza or conjunctivitis from March 25 to April 9, 2021.

\section{Controls}

Neighbors of cases in the affected kebeles who do not develop measles after follow-up of two incubation periods were considered as controls.

\section{Criteria for Inclusion and Exclusion Inclusion for Cases}

Any person who developed fever, maculopapular rash and/or cough, coryza, or conjunctivitis ${ }^{6}$ or laboratory confirmed measles IgM was included in the study.

\section{Exclusion}

Those who have vaccination history in the past two weeks were excluded because they develop measles symptoms as a result of an adverse event following immunization were excluded from the study.

\section{Inclusion for Controls}

Those who do not fulfill the measles case definition and those who had no previous history of measles infection were included as controls in the study.

\section{Exclusion}

Those who had previous history of measles infection were excluded because they develop immunity against measles.

\section{Sampling Size Determination}

Double population proportion formula was used to calculate sample size by using Epi Info software version 7 for the case-control study. The following parameters were considered: proportion of control exposed for four exposure variables (as depicted in the table below), adjusted odds ratio, confidence interval 95\%, power 80\%, ratio of case to control 1:2. Finally, a variable with large sample size selected from all (contact history with measles case with sample size of 180) 
Table I Sample Size Calculation for the Study Using Double Population Proportion

\begin{tabular}{|l|l|l|l|l|l|l|l|}
\hline Variable & \% In Unexposed & AOR & CI & Power & Ratio & Sample Size & Reference \\
\hline Contact & 23 & 2.72 & 95 & 80 & $1: 2$ & 180 & 31 \\
\hline Family size & 47 & 2.74 & 95 & 80 & $1: 2$ & 168 & 31 \\
\hline Distance >I hour from facility & 36.47 & 4.4 & 95 & 80 & $1: 2$ & 104 & 32 \\
\hline Mothers Age & 22 & 3.8 & $95 \%$ & 80 & $1: 2$ & 105 & 28 \\
\hline
\end{tabular}

and reference ${ }^{31}$ as depicted in Table 1. For the descriptive part all the 98 measles cases registered in the online list were used as a sample size. For case-control part 60 cases and 120 controls were recruited (Table 1).

\section{Sampling Technique}

We identified cases by active case searching using standard measles case definition in affected kebeles through house-tohouse searching and line listed.

After line listing, by using computer generated simple random sampling we select 60 cases for the case-control study and we conducted house-to-house search in affected kebeles for interviewing. For every one case, two neighborhoods of cases who do not develop symptoms of measles were identified from the adjustment of five households randomly. We recruited control after case subside, and two incubation periods passed or after 42 days ie starting from May 22, 2021.

\section{Cases and Controls Enrolment}

\section{Cases}

Cases were enrolled based on laboratory confirmed measles IgM or linked to confirmed cases epidemiologically.

\section{Controls}

Residents of Guradamole district who were living in the neighborhood of the case and who did not fulfill the case definition of measles were considered as controls.

\section{Operational Definition of Terms}

\section{Suspected Measles Case}

Any person with fever and generalized rash and/or cough, coryza or conjunctivitis. ${ }^{6}$

\section{Confirmed Measles Case}

A suspected case with laboratory confirmation (positive IgM antibody) or epidemiologically linked to confirmed cases in an outbreak. ${ }^{6}$

\section{Epidemiologically Linked Case}

A suspected measles case living in the same or in an adjacent district with a laboratory confirmed case where there is a likelihood of transmission; onset of rash of the two cases being within 30 days of each other. ${ }^{6}$

\section{Measles Death}

Any death from an illness that occurs in a confirmed case or epidemiologically linked case of measles within one month of the onset of rash. ${ }^{6}$

\section{Kebele}

The smallest administrative unit in Ethiopia. 


\section{Data Collection Method and Tool}

To confirm the existence of the outbreak five blood sample (serum specimen) were collected from active cases and sent to Hawassa Regional public health laboratory and all samples were positive for measles-specific IgM. A structured questionnaire adapted from different literature with the same objective was used after possible modification was made to answer the objective of the present study. The questionnaire was translated to Afaan Oromo language and translated back to English for consistency. Data about sociodemographic, exposure history to measles case, mother's knowledge about measles and availability of health service were collected by interviewing the mother or caregiver of the children. Data about immunization history were collected from immunization card and by history. We registered cases online during house-to-house searching of case and controls. Controls were identified from neighbor of cases. Data were collected by the deployed team, district public health emergency management (PHEM) officer, catchment health center PHEM focal person and health center director and one health extension in the affected kebele. Four years (2017-2020) routine immunization data was obtained from the district health office, to calculate and pool susceptible population for measles outbreak. In calculating administrative coverage, Ethiopian 2017 national population projection was used to obtain the birth cohort of each year.

\section{Data Analysis}

The collected data was entered and cleaned on EpiData version 3.1 software and exported to SPSS version 20 software for analysis. Descriptive statistics were used to characterize measles cases by person, place, and time. Case fatality rate (CFR), an attack rate (AR), and age specific attack rate (ASAR) were also calculated. Bivariate logistic regression was used to select candidate variables at $P$-value of $<0.25$ and then, multiple logistic regression conducted by employing backward elimination method to identify the statistically significant risk factors for measles infection by controlling the possible confounder. To identify the predictor variable $95 \%$ confidence interval (CI) and $P$-value $<0.05$ were calculated. Multicollinearity diagnosis conducted and no variable with greater than 10 VIF observed. Descriptive data was presented by using tables, charts, histogram and narrative statements.

\section{Vaccine Effectiveness}

Vaccine effectiveness (VE) was calculated by using the formula VE $=(\mathrm{PPV}-\mathrm{PCV}) / \mathrm{PPV}(1-\mathrm{PCV})=$ where $\mathrm{PPV}$ is the proportion of peoples vaccinated and PCV is proportion of cases vaccinated. ${ }^{33,34}$ The vaccine effectiveness was calculated for children age group of 9 months to 59 months children because of Ethiopian routine measles immunization starts at nine months ${ }^{6}$ and the outbreak in Guradamole district primarily affected children aged less than 5 years.

\section{Measurement}

To assess nutritional status of cases and controls we used body mass index (BMI) or weight for height measurement. ${ }^{28,35}$ To measure weight for height of children $<23$ months of age or $<87 \mathrm{~cm}$ long lying down and for children 24-59 months of age and above or taller than $87 \mathrm{~cm}$ standing up. The standardized WHO table (Z-score) was used to interpret the result of weight for height. ${ }^{31,36,37}$ Those who had malnutrition were linked to an adjacent health facility for treatment.

\section{Data Quality Management}

Measles case definition was clearly defined to ensure that all cases included in the study are based on the set case definition criteria and to minimize misclassification bias. To avoid selection bias and increase representativeness of the study finding, both cases and controls were registered from community. The supervisors and data collectors were appropriately orientated. Daily supervision was conducted by the principal investigator for completeness and consistency of the collected data. Double data entry verification was conducted to minimize data entry error.

\section{Ethical Clearance}

Ethical clearance was obtained from Bale Zone health office ethical review committee under the reference number ref. no. EFG 27261 and was conducted in accordance with Declaration of Helsinki for human subjects. The ethical review 
Table 2 Table Showing Age Specific Attack Rate of the Outbreak

\begin{tabular}{|l|l|l|l|l|}
\hline S. No & Age Category by Month & Measles Cases & Population at Risk & Attack Rate AR/I000 \\
\hline 1 & $0-59$ & 66 & 1743 & 37.88 \\
\hline 2 & $60-108$ & 15 & 1980 & 7.58 \\
\hline 3 & $109-168$ & 9 & 1873 & 4.81 \\
\hline 4 & $169-228$ & 5 & 1067 & 4.69 \\
\hline 5 & $229-288$ & 2 & 818 & 2.45 \\
\hline 6 & $289-348$ & 1 & 865 & 1.16 \\
\hline 7 & Total & 98 & 8345 & 11.74 \\
\hline
\end{tabular}

committee also approved verbal informed consent at individual level because of the following reasons. First, the study is an outbreak investigation so it does not present more than minimal risk of health problem to participants and involves no procedures for which written consent is normally required outside of the investigation context. Second, the investigation was conducted in pastoralist area where illiteracy is more prevalent and participants were unable to read the information sheet. For participants under 18 years the mother or caregiver provide informed verbal consent. Prior to data collection participants/caregivers were informed about the objective of the study and their willingness to participate in the study, also informed they have right to interrupt the interview at any time. Confidentiality was assured, we used codes instead of any personal identifiers and we used their information only for the investigation purpose.

\section{Results}

\section{Descriptive Epidemiology}

Index case of this outbreak was a 24 year-old person who was traveled to Delo-mena woreda on February 11, 2021. He was also traveled to the Somali region (Qundi district) on February 13, 2021 and on return traveled to Batu goxi, Hokoltu kebele. The index case has unknown vaccination status against measles.

A total of 98 measles cases and seven related deaths with crude case fatality rate of (CFR 7.15\%) were registered from February 20 to April 10, 2021 from Guradamole district. The outbreak started on February 20, 2020, reached climax level March 10, 2021 and subsided on April 10, 2021. Of the total cases, 44 (45\%) were females and 54 (55\%) were males. Only eight (8.2\%) measles cases were treated as inpatients and $90(91.8 \%)$ were treated as an outpatients. Five cases $(5.10 \%)$ were laboratory confirmed and 93 (94.8\%) cases were epidemiologically linked. The overall attack rate of the outbreak is 12/1000 and higher among 0-59 month-old children (37.88/1000) (Table 2).

\section{Attack Rate by Affected Kebeles}

The current outbreak attack affected five kebeles of the district and the attack rate (AR) of the affected kebeles was 8.3/ 1000 population. The highest number of cases were observed from Hokoltu and Funale Kusi kebeles of the district with $76(78 \%)$ and $9(9.2 \%)$ cases, respectively as shown in Table 3.

\section{Cases by Age}

Regarding measles cases by age category 0-59 and 60-108 months were the most affected in the current outbreak with $65(67.3 \%)$ and $15(13.3 \%)$ of cases respectively. The number of cases decreased among the older age group two (2\%) in 229-288 months as shown in Figure 1.

\section{Measles Cases by Time}

The outbreaks started on February 21, 2021 and subsided on April 9, 2021. The first measles case was reported on February 21, 2021 from Hokoltu kebele of Guradamole on the fourth day February 25, 2021 after the first case 
Table 3 Table Showing Attack Rate of the Outbreak by Kebeles of the District

\begin{tabular}{|l|l|r|r|}
\hline S. No & Kebele & Number of Cases & Percent (\%) \\
\hline 1 & Hokoltu & 76 & 77.6 \\
\hline 2 & Funale Kusi & 9 & 9.2 \\
\hline 3 & Alhashana & 4 & 4.1 \\
\hline 4 & Engoye llani & 6 & 6.1 \\
\hline 5 & Yubdo Sere & 3 & 3 \\
\hline & Total & 98 & 100 \\
\hline
\end{tabular}

the second incubation period occurred. The Epi curve has several peaks showing propagated type of transmission. The outbreak lasts for 48 days. The outbreak reached climax on March 10 and no cases were reported after April 9, 2021 as shown in Figure 2 below.

\section{Age and Sex Specific Case Fatality Rate}

The case fatality rate (CFR) of the outbreak was seven (7.2\%), of which four (57\%) were females and three $(43 \%)$ were males. Regarding age specific case fatality rate (ASCFR) about four (57\%) were children less than 0-59 months and three $(43 \%)$ were $60-108$ month-old children.

\section{Symptom Development}

According to the results of this study all cases developed measles symptoms like fever, maculopapular rash and cough and 68 (69.4\%) of the cases developed conjunctivitis. Regarding complications, 18 (18.4\%), 12 (12.25), and eight (8\%) cases developed diarrhea, pneumonia, and otitis media, respectively (Table 4).

\section{Vaccination Status of Cases}

From the total of 98 measles cases registered four (4.08\%) of them were not eligible (less than nine months) for MCV1. Regarding vaccination with MCV of the 94 cases reported about 71 (75.5\%) of them were unvaccinated and 24 (24.5\%) vaccinated with one dose only. Unknown vaccination status was two (4\%) (Figure 3).

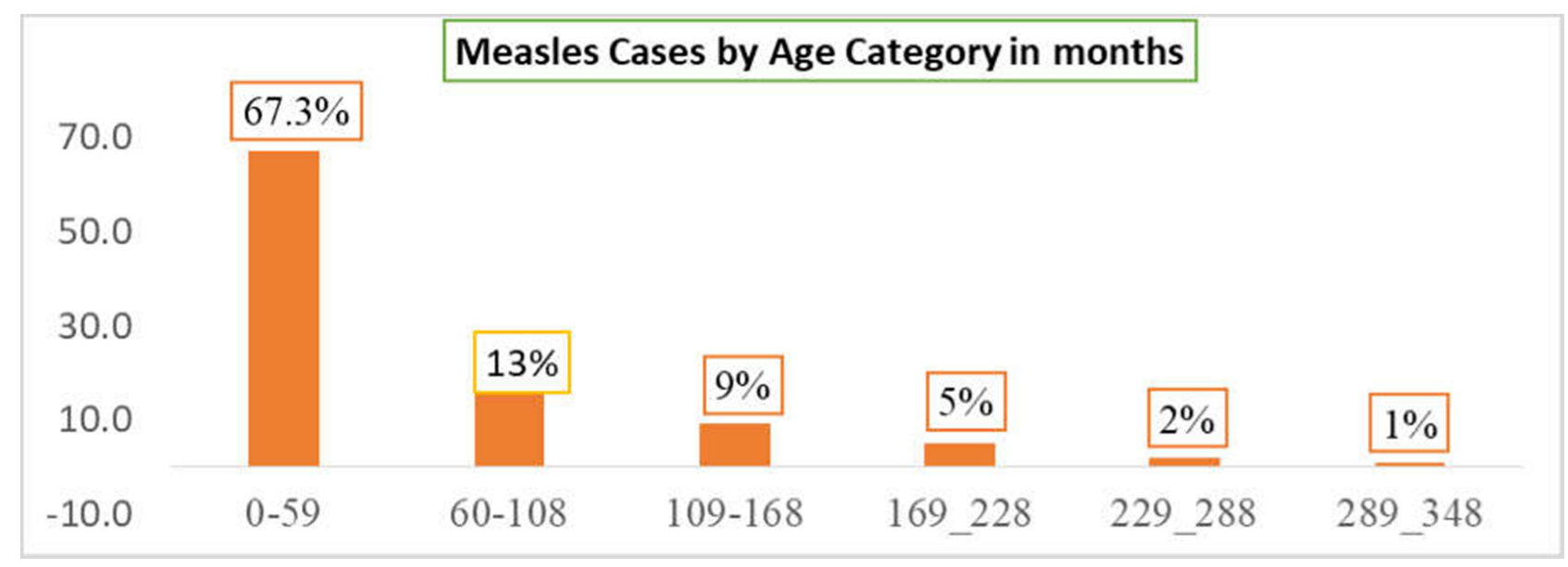

Figure I Measles cases by age category, Guradamole District, Bale Zone, Southeastern Ethiopia, 202 I. 


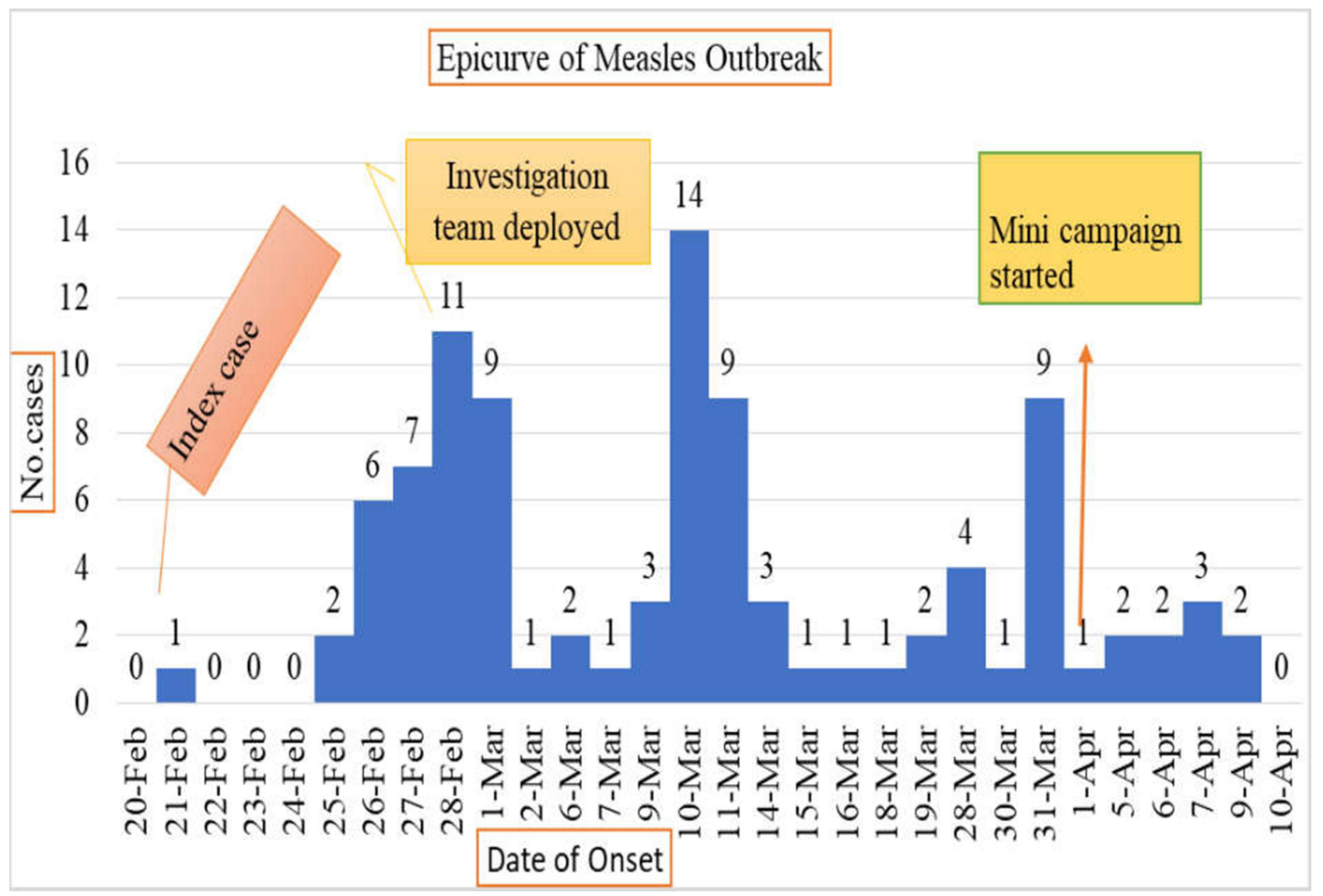

Figure 2 Epi curve showing date of onset symptom and number of measles cases reported in Guradamole District, Bale Zone, Southeastern Ethiopia, 2021.

\section{Measles Outbreak Risk Analysis}

Measles vaccination coverage and susceptible pooling - four years (2017-2020) administration data about routine measles immunization (MCV1) coverage and supplementary immunization activity (SIA) conducted in the district was obtained from Guradamole district health office. District routine MCV1 coverage were $74.5 \%$ for the last consecutive four years 2017-2020 GC. In Hokoltu kebele there is no functional health post or refrigerator, as a result,

Table 4 Table Showing Percent of Measles Cases with Signs and Symptoms

\begin{tabular}{|l|l|l|l|}
\hline \multirow{2}{*}{ S. No } & \multirow{2}{*}{ Type of Symptom } & \multicolumn{2}{|l|}{ Develop Symptoms } \\
\cline { 3 - 4 } & & Number & Percent \\
\hline 1 & Rash & 98 & 100 \\
\hline 2 & Fever & 98 & 100.0 \\
\hline 3 & Cough & 98 & 100.0 \\
\hline 4 & Diarrhea & 18 & 18.4 \\
\hline 5 & Pneumonia & 12 & 12.2 \\
\hline 6 & Conjunctivitis & 68 & 69.4 \\
\hline 7 & Coryza & 55 & 56.1 \\
\hline 8 & Otitis media & 8 & 8 \\
\hline
\end{tabular}




\section{Vaccination Status of Cases}

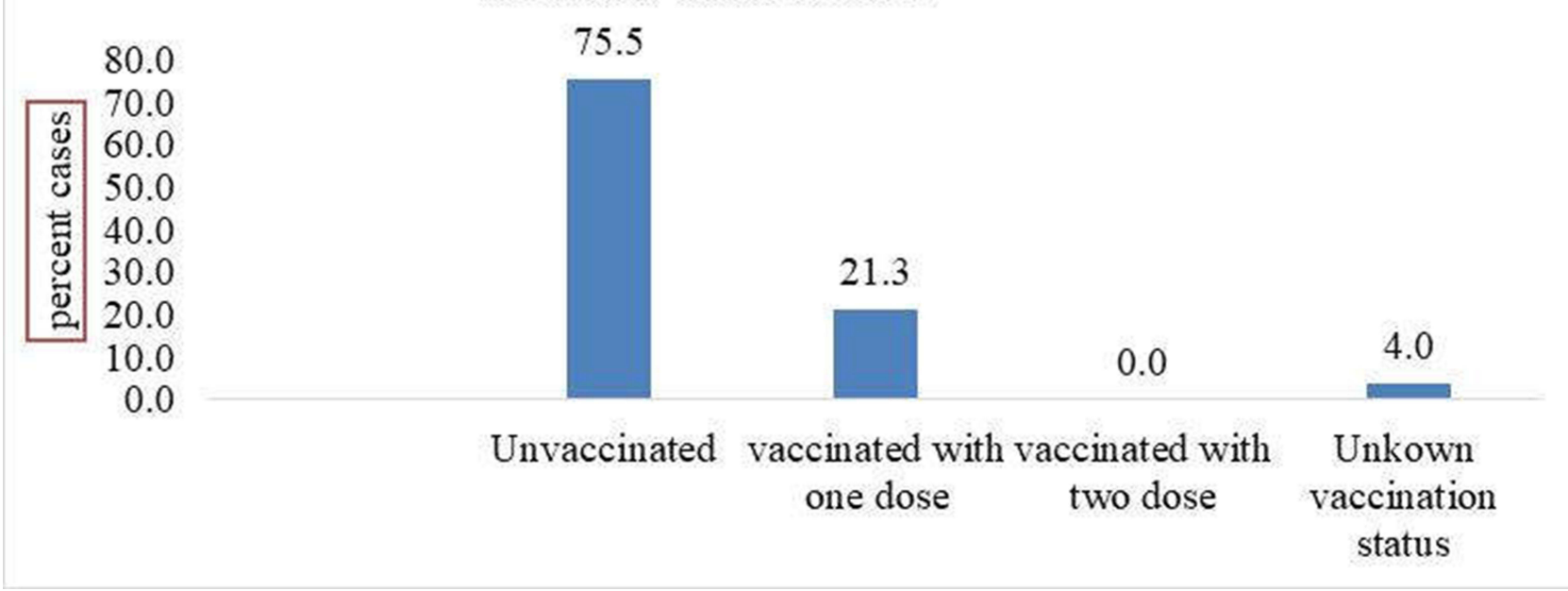

Figure 3 Graph showing vaccination status of cases Guradamole District, Bale Zone, Southeastern Ethiopia, 2021.

providing routine immunization was very tough. To estimate the risk of measles outbreak we have calculated measles susceptible accumulation and there are about 412 (31.5\%) of under five year old children remaining unvaccinated from 2017-2020. So around one-third of birth cohort of 2020 remained unvaccinated or susceptible for measles from 20172020, and based on WHO criteria for priority for large measles outbreak, the district is not high priority.

\section{Vaccine Effectiveness}

Vaccine effectiveness was calculated for 9-59 months. Proportion of people vaccinated (PPV) $=0.706$ and proportion of cases vaccinated were 0.27 by substituting vaccine effectiveness (VE) is $82.6 \%$.

\section{Analytic Epidemiology Sociodemographic Characteristic}

A total of 60 cases and 120 controls were recruited with a ratio of case to control of $1: 2$. The mean age of the cases is 1.8 months ( $\mathrm{SD} \pm 0.417)$ and for controls 1.67 months ( $\mathrm{SD} \pm 0.43)$. Regarding age, about $31(52 \%)$ of cases and $67(56 \%)$ of controls were in the age category of $12-59$ months. About $34(57 \%)$ of the cases and $52(43 \%)$ of controls were males. The families of around $41(68 \%)$ of cases and $68(57 \%)$ of controls were pastoralists. Regarding educational status of the caregivers, $40(66.6 \%)$ of cases and $60(50 \%)$ of controls have no formal education (Table 5).

Bivariate analysis was conducted and all variables with $P$-value of $<0.25$ were selected for multivariate analysis (Table 6).

\section{Multivariate Analysis}

All candidate variables selected from the bivariate analysis were entered in multivariate logistic regression to identify the independent predictors of measles infection. Having history of contact with a measles case increases the odds of contracting measles (AOR: 3.24, 95\%CI: 1.03-10.17) times more likely compared to others who do not have contact history with a measles case. Being unvaccinated increases the likelihood of contracting measles (AOR: 5.66, 95\%CI: 1.124-25.81) times more likely, compared to those who had vaccination history.

Those who have moderate acute malnutrition were (AOR: 4.34, 95\%CI: 2.14-8.81) times more likely to be infected with measles compared to the normal ones. Being in a 30-60-minute or greater than 61 minutes walking distance from the nearesthealth facility increases the risk of measles infection (AOR: 3.9, 95\%CI: 1.03-14.86) and (AOR: 3.99, 95\%CI: 1.31-12.19) times more, respectively, compared to those less than 30 minutes walking distance from the nearest health 
Table 5 Table Showing Sociodemographic Characteristic of Cases and Controls

\begin{tabular}{|c|c|c|c|c|c|}
\hline Variables & Category & Cases N (\%) & Controls N (\%) & Sig. & COR \\
\hline \multirow[t]{3}{*}{ Age of the child } & $<12$ months & $19(31.6)$ & $29(24)$ & 0.549 & I \\
\hline & $12-59$ months & $31(5 \mathrm{I} .6)$ & $67(56)$ & 0.343 & 1.416 \\
\hline & $60-168$ months & $10(16.6)$ & $24(20)$ & 0.344 & 1.572 \\
\hline \multirow[t]{2}{*}{ Sex of the child } & Male & $34(57)$ & $51(42.5)$ & 0.073 & 1.333 \\
\hline & Female & $26(43)$ & $69(57.5)$ & 0.741 & 0.848 \\
\hline \multirow[t]{2}{*}{ Family's ethnic group } & Oromo & $49(82)$ & $109(91)$ & 0.199 & 0.522 \\
\hline & Somali & II (I8) & II (9) & 0.880 & I \\
\hline \multirow[t]{4}{*}{ Marital Status of mother/care giver } & Married & $45(75)$ & $104(82)$ & 0.442 & I \\
\hline & Divorced & $5(8.4)$ & $6(5)$ & 0.685 & 0.720 \\
\hline & Widow & $6(10)$ & $4(3)$ & 0.599 & 0.696 \\
\hline & Single & $4(6.6)$ & $6(5)$ & 0.119 & 0.341 \\
\hline Religion of mother/care giver & Muslim & $60(100)$ & $120(100)$ & & \\
\hline \multirow[t]{3}{*}{ Occupation of the mother/care giver } & Pastoralist & $41(68)$ & $68(57)$ & 0.118 & I \\
\hline & Farmer & $15(25)$ & $35(29)$ & 0.147 & 1.719 \\
\hline & Housewife & $4(7)$ & $17(14)$ & 0.109 & 6.136 \\
\hline \multirow[t]{2}{*}{ Family size } & $<4$ & $33(55)$ & $73(61)$ & & I \\
\hline & $>5$ & $27(45)$ & 47 (39) & 0.478 & 0.782 \\
\hline \multirow[t]{3}{*}{$\begin{array}{l}\text { Educational status of the mother/care } \\
\text { giver }\end{array}$} & $\begin{array}{l}\text { No formal } \\
\text { education }\end{array}$ & $41(68)$ & $60(50)$ & 0.118 & I \\
\hline & Primary I-8 & $18(30)$ & $52(43)$ & 0.147 & 1.719 \\
\hline & Secondary 9-12 & I (2) & $8(7)$ & 0.109 & 6.136 \\
\hline
\end{tabular}

facility. Having travel history of 10-14 days in the measles-affected area increases the likelihood of measles infection (AOR: 3.99, 95\%CI: 1.31-12.19) times, compared to those who had no travel history (Table 7).

\section{Discussion}

A measles outbreak was reported from Guradamole district on February 25, 2021. A total of 98 cases with seven (7\%) deaths were reported in 48 days. All five samples sent to Hawassa Regional Laboratory were positive for measles IgM. About $44(45 \%)$ of the cases were females and (55\%) were males. The attack rate was 12/1000 and high attack rate occur among 0-59 month-olds (38/1000). All cases developed measles symptoms, fever, maculopapular rash, and cough 100\%. Vaccination coverage of the district was very low at $74.4 \%$.

Consistent with the result of outbreak investigations conducted in Ethiopia, ${ }^{38,49}$ in this investigation age specific attack rate among 0-59 month-old children were 38/1000 population. The result of this investigation is in line with other investigations conducted in Sudan, India and Nepal, which resulted in high attack rate among children under five years. ${ }^{29,39}$

Case fatality of this investigation is $7.2 \%$ inline compared with finding of investigation conducted in India $7 \% .{ }^{40}$ But the finding is higher compared to an outbreak investigation conducted in Ginir and Artuma districts of the Oromia region of Ethiopia $0.5 \%$ and $2.6 \%$, respectively. ${ }^{24,38}$ The difference is due to the current outbreak occurring among a pastoralist population with higher food insecurity and prevalent malnutrition, which increased fatality from measles.

Vaccination coverage of the district was low (74\%) compared to WHO recommendations achieving and maintenance of $95 \%$, of two doses of measles vaccine by routine immunization program and supported by supplementary immunization activities to eliminate measles. ${ }^{18,41}$ The coverage, which is less than $95 \%$, is not expected to develop herd immunity in the community so outbreaks of vaccine-preventable disease occur frequently in such districts.

Regarding vaccination with MCV, of 98 cases reported about 74 (75.5\%) of cases were unvaccinated. A study conducted in Nepal shows $64 \%$ of cases were vaccinated with measles containing vaccine $(\mathrm{MCV})^{39}$ and an investigation 
Table 6 Table Showing Candidate Variables in Bivariate Logistic Regression for the Multivariate Analysis

\begin{tabular}{|c|c|c|c|c|c|c|c|}
\hline \multirow[t]{2}{*}{ Variable } & \multirow[t]{2}{*}{ Category } & \multicolumn{2}{|l|}{ Status } & \multirow[t]{2}{*}{ Sig. } & \multirow[t]{2}{*}{ COR } & \multicolumn{2}{|l|}{$95 \% \mathrm{Cl}$} \\
\hline & & $\begin{array}{l}\text { Cases } \\
\mathbf{N}(\%)\end{array}$ & $\begin{array}{l}\text { Controls } \\
\mathbf{N}(\%)\end{array}$ & & & Lower & Upper \\
\hline Contact history & $\begin{array}{l}\text { Yes } \\
\text { No }\end{array}$ & $\begin{array}{l}35(58) \\
25(42)\end{array}$ & $\begin{array}{l}26(22) \\
94(78)\end{array}$ & $\begin{array}{l}0.00 * \\
1\end{array}$ & 5.062 & 2.584 & 9.915 \\
\hline Travel history before 14 days & $\begin{array}{l}\text { Yes } \\
\text { No }\end{array}$ & $\begin{array}{l}32(53) \\
28(47)\end{array}$ & $\begin{array}{l}26(22) \\
94(78)\end{array}$ & $\begin{array}{l}0.00^{*} \\
1\end{array}$ & 4.132 & 2.119 & 8.056 \\
\hline $\begin{array}{l}\text { Knowledge about measles is vaccine } \\
\text { preventable }\end{array}$ & $\begin{array}{l}\text { Yes } \\
\text { No }\end{array}$ & $\begin{array}{l}17(28) \\
43(72)\end{array}$ & $\begin{array}{l}63(52) \\
57(48)\end{array}$ & $\begin{array}{l}0.002^{*} \\
1\end{array}$ & 0.358 & 0.184 & 0.696 \\
\hline Visited mosque within 10 days & $\begin{array}{l}\text { Yes } \\
\text { No }\end{array}$ & $\begin{array}{l}30(50) \\
30(50)\end{array}$ & $\begin{array}{l}17(9) \\
103(57)\end{array}$ & $\begin{array}{l}0.00 * \\
1\end{array}$ & 6.059 & 2.947 & 12.456 \\
\hline Knowledge about measles transmission & $\begin{array}{l}\text { Yes } \\
\text { No }\end{array}$ & $\begin{array}{l}26(43) \\
34(57)\end{array}$ & $\begin{array}{l}38(21) \\
82(79)\end{array}$ & $\begin{array}{l}0.085 * \\
1\end{array}$ & 1.65 & 0.871 & 3.127 \\
\hline Nutritional status & $\begin{array}{c}\text { Moderate acute } \\
\text { malnutrition } \\
\text { Normal }\end{array}$ & $\begin{array}{l}27(15) \\
33(18)\end{array}$ & $\begin{array}{l}19(1 \mathrm{I}) \\
101(56)\end{array}$ & $\begin{array}{l}0.00 * \\
1\end{array}$ & 4.349 & 2.146 & 8.814 \\
\hline Vaccination status & $\begin{array}{l}\text { Unvaccinated } \\
\text { Vaccinated } \\
\text { Unknown }\end{array}$ & $\begin{array}{l}4 \mid(68.3) \\
\text { I7 (28.3) } \\
2(3.3)\end{array}$ & $\begin{array}{l}61(5 \mathrm{I}) \\
55(46) \\
5(4.2)\end{array}$ & $\begin{array}{l}0.025^{*} \\
1 \\
0.128\end{array}$ & $\begin{array}{l}5.667 \\
3.4\end{array}$ & $\begin{array}{l}1.244 \\
0.703\end{array}$ & $\begin{array}{l}25.813 \\
16.436\end{array}$ \\
\hline Distance from health center & $\begin{array}{c}30 \text { minutes } \\
31-60 \text { minutes } \\
>\text { One hour }\end{array}$ & $\begin{array}{l}19(31.5) \\
13(21.5) \\
28(47)\end{array}$ & $\begin{array}{l}16(13.3) \\
28(23.3) \\
76(63.3)\end{array}$ & $\begin{array}{l}1 \\
0.018^{*} \\
0.002 *\end{array}$ & $\begin{array}{l}3.663 \\
4.344\end{array}$ & $\begin{array}{l}1.248 \\
1.687\end{array}$ & $\begin{array}{l}10.755 \\
11.187\end{array}$ \\
\hline Previous measles infection & $\begin{array}{l}\text { YES } \\
\text { No }\end{array}$ & $\begin{array}{l}4 \\
56\end{array}$ & $\begin{array}{l}17 \\
103\end{array}$ & $\begin{array}{l}0.14 * \\
\mathrm{I}\end{array}$ & 0.541 & 0.218 & 1.339 \\
\hline Presence of heath facility & $\begin{array}{l}\text { Yes } \\
\text { No }\end{array}$ & $\begin{array}{l}26(14) \\
34(20)\end{array}$ & $\begin{array}{l}59(33) \\
61(34)\end{array}$ & $\begin{array}{l}0.055^{*} \\
1\end{array}$ & 0.791 & 0.424 & 1.475 \\
\hline Presence of measles case in the family & $\begin{array}{l}\text { Yes } \\
\text { No }\end{array}$ & $\begin{array}{l}29(16) \\
31(17)\end{array}$ & $\begin{array}{l}27(15) \\
93(52)\end{array}$ & $\begin{array}{l}0.665 \\
1\end{array}$ & 3.222 & 1.66 & 6.255 \\
\hline Sick with other disease & $\begin{array}{l}\text { Yes } \\
\text { No }\end{array}$ & $\begin{array}{l}33(18) \\
27(15)\end{array}$ & $\begin{array}{l}28(15.6) \\
92(5 I)\end{array}$ & $\begin{array}{l}0.00 * \\
1.00\end{array}$ & 4.016 & 2.072 & 7.782 \\
\hline Vaccine doses & $\begin{array}{l}\text { One dose } \\
\text { Two doses }\end{array}$ & $\begin{array}{l}\text { II (6) } \\
8(4.4)\end{array}$ & $\begin{array}{l}\text { II (6) } \\
10(5.6)\end{array}$ & $\begin{array}{l}0.095 * \\
1\end{array}$ & 1.25 & 0.358 & 4.363 \\
\hline
\end{tabular}

Notes: I=reference variable, *significant at $P$-value 0.25 .

in Uganda finding vaccine coverage of $69 \%{ }^{33}$ greater than finding of an investigation conducted in Kerala where $48 \%$ of cases are unvaccinated. ${ }^{44}$ The difference is due to the outbreak occurring among the pastoralists who have no access to routine primary health care service like RI and missed SIA immunization.

Vaccination effectiveness was calculated to be $82.6 \%$ among cases observed in children in the age group of 9-59 months higher compared to the results of investigations conducted in Uganda, Kerala, and Pakistan with vaccination effectiveness of $75 \%, 76.6 \%$, and $78 \%$, respectively. ${ }^{33,44,45}$ The effectiveness was less than $85 \%$ because of factors like poor vaccine storage, poor cold chain management at the district. The vaccine also travels from store to kebeles an average of $65-110 \mathrm{~km}$ by motor bicycle with vaccine carrier and there is no suitable condition to change the ice pack, which dangerously affects vaccine effectiveness. 
Table 7 Variables Independently Associated with Measles Infection in Multivariate Logistic Regression

\begin{tabular}{|c|c|c|c|c|c|c|c|}
\hline \multirow[t]{2}{*}{ Variable } & \multirow[t]{2}{*}{ Category } & \multicolumn{2}{|c|}{ Status } & \multirow[t]{2}{*}{$P$-value } & \multirow[t]{2}{*}{ AOR } & \multicolumn{2}{|c|}{$95 \% \mathrm{Cl}$} \\
\hline & & Cases N (\%) & Controls N (\%) & & & Lower & Upper \\
\hline \multirow[t]{3}{*}{ Vaccination Status } & Unvaccinated & $4 \mid(68,3)$ & $6 I(5 I)$ & 0.034 & 2.619 & 1.077 & 6.369 \\
\hline & Vaccinated & $17(28.3)$ & $55(46)$ & $I^{*}$ & & & \\
\hline & Unknown & $2(3.3)$ & $5(4.2)$ & 0.066 & 7.103 & $0.88 \mathrm{I}$ & 57.247 \\
\hline \multirow[t]{2}{*}{ Nutritional status } & Moderate acute malnutrition & $22(36.6)$ & $18(15)$ & 0.012 & 3.214 & 1.297 & 7.969 \\
\hline & Normal & $33(55)$ & $91(76)$ & $I^{*}$ & & & \\
\hline \multirow[t]{3}{*}{ Distance from health facility } & 30 minutes & $19(31.5)$ & $16(13)$ & $I^{*}$ & & & \\
\hline & $31-60$ minutes & $13(2 \mid .5)$ & $28(23)$ & 0.045 & 3.913 & 1.031 & 14.860 \\
\hline & $>60$ minutes & $28(47)$ & $76(63)$ & 0.012 & 4.585 & 1.391 & 15.112 \\
\hline \multirow[t]{2}{*}{ Travel before 14 days } & Yes & $32(53)$ & $26(22)$ & 0.015 & 3.996 & 1.310 & $12.19 \mid$ \\
\hline & No & $28(47)$ & $94(78)$ & $I^{*}$ & & & \\
\hline \multirow[t]{2}{*}{ Contact history } & Yes & $17(28)$ & $10(8)$ & 0.044 & 3.243 & 1.034 & 10.175 \\
\hline & No & $43(72)$ & $110(92)$ & $I^{*}$ & & & \\
\hline
\end{tabular}

Notes: $-I=$ shows reference variable, *Significant at $P$-value 0.05 .

According to observation and record review findings at the district results show, poor vaccine storage, poor electric access, and poor cold chain maintenance at district and health center, high environmental temperature and no transportation to kebeles. Not storing in recommended compartment, storing vaccine at temperature of greater than $2-8^{\circ} \mathrm{C}$ or less than $-15^{\circ} \mathrm{C}$ can decrease vaccine potency. ${ }^{18}$

Having history of contact with a confirmed measles case increases the odds of contracting measles by 3.24 times, compared to those who do not have contact with a measles case. The finding of this investigation supports the finding of previous investigations conducted in Artuma Fursi, Oromia, Ethiopia. ${ }^{39}$ Another investigation in Zimbabwe shows that having contact history with a measles case increased risk of contracting measles by 41 times. ${ }^{26}$ Because the measles virus is highly contagious, contact with any person who is infected increases the spread of measles transmission and infection.

The risk of being infected with measles is 5.66 times more likely in those who are unvaccinated than in those who have vaccination history. In line with the results of study conducted in Kerala unvaccinated children were 5.6 time more likely to develop measles. ${ }^{44}$ Our finding is line with an investigation conducted in Nigeria, where being unvaccinated increases by 14 times the risk of measles infection. ${ }^{46}$ Conversely, different literature showed that homogeneous high vaccination coverage with two doses of measles vaccine is the cornerstone required for ensuring and sustaining high population immunity against measles. ${ }^{1,4,28}$

Moderate acute malnutrition increases the likelihood of measles infection by 4.34 times, compared to the normal. In line with the result of an outbreak investigation conducted in the Afar region of Ethiopia, malnutrition increases the likelihood of being infected with the measles virus. ${ }^{47} \mathrm{~A}$ study conducted in India shows positive correlation between measles and malnutrition, being undernourished, including vitamin A deficiency, increases the chance contracting measles and of fatality. ${ }^{6}$ Undernourished children are most vulnerable to measles and whenever outbreaks occur, adequate public health prevention measures must be taken to avoid further expansion of the disease. ${ }^{43}$ Malnutrition suppresses the immunity of children and increases the likelihood of infection with measles.

The odds of being infected with measles were 3.91 and 3.99 times more likely in those 31-60 and greater than 61 minutes walking distance from a health facility. Our finding is supporting the result of an outbreak investigation conducted in the Congo and South Ethiopia where residing in a distance greater than 30 minutes walk from health facility increases the risk of measles infection by threefold higher than the counterparts. ${ }^{48}$ The current outbreak occurred in a remote kebele and they walk $70-110 \mathrm{~km}$ to reach the health center and as distance from facility increases the probability of getting basic health care service and early treatment of cases decrease. 
The odds of contracting measles were 3.99 times more likely in those who had travel history within 10-14 days. In line with study conducted in Gindhir and Artuma Fursi districts of Ethiopia results, having travel history to an area infected with active measles would increase the likelihood of contracting measles infection by four times compared to those who had no history of travel. ${ }^{24,38}$ This is due to measles being highly contagious and transmission is through person-to-person contact.

\section{Limitation of the Study}

Recall bias may occur during data collection of variables like immunization status, vaccination dose taken, and other since it is common in a case-control study.

\section{Conclusion}

The highest attack rate was observed among 0-59 month-old children. The outbreak case fatality rate is very high $7.1 \%$. The pooled MCV1 coverage of the district was very low $74 \%$ in 2017-2020, which was less than the expected $95 \%$ to develop herd immunity. Vaccine effectiveness was $82.6 \%$ lower than the expected $85 \%$ effectiveness of measles vaccine. Being unvaccinated, acute malnutrition, contact history with measles case, distance from health center and having travel history within 14 days were found the independent predictors of measles outbreak. The routine EPI of the district was not functioning well and not accessible to the internally displaced people (IDP) and pastoralist population in the district. Cold chain, vaccine storage and transportation to health facilities were not as recommended to keep vaccine safety.

\section{Recommendation}

The factors related to low vaccine effectiveness like cold chain management must be improved at storage in facility and at vaccination sites in the district. Identifying pastoralists should register all eligible children with their respective appointment exchange and communicate with adjacent districts to vaccinate upon migration from one district to another district must also be considered by the district.

Periodic program-specific supportive supervision to health center and health posts, review meeting and randomly assessing vaccination status of eligible children is recommended to solve a problem with utilization and false report. Step-up of nutritional status of children is also mandatory to achieve the measles elimination goal and to sustain it subsequently.

Counseling and health education of mothers about measles vaccine, vaccine-preventable disease and schedule of vaccination for their children on timely basis must be promoted among health professionals in the district The vaccination coverage of the district was very low, which needs further research studies to identify the possible determinant factors like knowledge about vaccination and vaccine-preventable disease that leads to nonvaccination of the eligible children in district.

\section{Acknowledgments}

We would like to express our deepest gratitude and apprehension to Almighty God. We also appreciate Ethiopian Field Epidemiology and laboratory training program and Jimma University. We are also grateful to all Bale Zone health office and Guradamole district health office for their cooperation in this study. Lastly, we would like to expand our thanks to data collectors and study participants.

\section{Author Contributions}

All authors contributed a significant contribution to the work reported, whether that is in the conception, study design, execution, acquisition of data, analysis and interpretation of data, or in all these areas; took part in drafting, revising or critically reviewing the article; gave final approval of the version to be published; have agreed on the journal to which the article has been submitted; and agree to be accountable for all aspects of the work. 


\section{Funding}

There is no funding to report.

\section{Disclosure}

The authors report no conflicts of interest in this work.

\section{References}

1. World Health Organization. National immunization coverage scorecards estimates for 2017 global immunization coverage in 2017; 2017. Available from: https://apps.who.int/iris/handle/10665/276969. Accessed February 3, 2022.

2. [No authors listed]. Measles vaccines: WHO position paper - April 2017. Wkly Epidemiol Rec. 2017;92(17):205-227.

3. World Health Organization. Surveillance guide for vaccine-preventable diseases in the WHO South-East Asia Region; 2017. Available from: https://apps.who.int/iris/rest/bitstreams/1168845/retrieve. Accessed February 3, 2022.

4. World Health Organization. Measles outbreaks strategic response plan 2021-2023; 2021. Available from: https://apps.who.int/iris/bitstream/handle/ 10665/340657/9789240018600-eng.pdf. Accessed February 3, 2022.

5. College Board. AP Program Participation and Performance Data 2020; 2020. Available from: https://research.collegeboard.org/programs/ap/data/ participation/ap-2020. Accessed January 21, 2022.

6. Ethiopian Health and Nutrition Research Institute, Federal Democratic Republic of Ethiopia. Guideline on measles surveillance and outbreak management; 2012. 3rd edition.Available from: https:/www.ephi.gov.et/images/guidelines/guideline-on-measles-surveillance-and-outbreak-manage ment2012.pdf. Accessed February 3, 2022.

7. World Health Organization. Emergencies preparedness, response. Measles - global situation; 2019. Available from: https://reliefweb.int/sites/ reliefweb.int/files/resources/WHO\%20_\%20Measles\%20\%E2\%80\%93\%20Global\%20situation.pdf. Accessed February 3, 2022.

8. European Centre for Disease Prevention and Control. Who is at risk for measles in the EU/EEA? Identifying susceptible groups to close immunity gaps towards measles elimination; 2019. Available from: https://www.ecdc.europa.eu/sites/default/files/documents/RRA-Measles-EU-EEA-May2019.pdf. Accessed February 3, 2022.

9. Thompson KM. What will it take to end fatalities from measles? Lancet Glob Heal. 2019;7(4):E394-E395. doi:10.1016/S2214-109X(19)30050-6

10. World Health Organization, Regional Office for Africa. African regional guidelines for measles and rubella surveillance WHO Regional Office for Africa; 2015. Available from: https://www.afro.who.int/sites/default/files/2017-06/who-african-regional-measles-and-rubella-surveillance-guide lines_updated-draft-version-april-2015_1.pdf. Accessed February 3, 2022.

11. World Health Organization. Global vaccine action plan. Regional reports on progress towards GVAP-RVAP goals. Annex to the GVAP secretariat annual report 2018; 2018. Available from: https://www.who.int/immunization/global_vaccine_action_plan/web_regional_gvap_reports_2018.pdf. Accessed February 3, 2022.

12. Ethiopian Public Health Institute. Ethiopia; Mini Demographic and Health Survey 2019; 2019. Available from: https://www.unicef.org/ethiopia/ media/1721/file/The\%202019\%20Ethiopia\%20Mini\%20Demographic\%20and\%20Health\%20Survey\%20.pdf. Accessed February 3, 2022.

13. Hailu D, Alano A, G/Mariam A, Abicho T. Measles; For the Ethiopian health center team; 2005. Ethiopia Public Health Training Initiative, The Carter Center, the Ethiopia Ministry of Health, and the Ethiopia Ministry of Education. Available from: https://www.cartercenter.org/resources/pdfs/ health/ephti/library/modules/degree/mod_measles_final.pdf. Accessed February 3, 2022.

14. U.S. Agency for International DevelopmentAudit of Feed the Future Activities in Ethiopia, Audit Report No. 4-663-13-005-p, March 1, 2013. Available from: https://pdf.usaid.gov/pdf_docs/PBAAC740.pdf. Accessed February 22, 2022.

15. Chung EK, Rhee JA, Baik YH, A OS. The effect of team-based learning in medical ethics education. Med Teach. 2009;31(11):1013-1017. doi: $10.3109 / 01421590802590553$

16. World Health Organization; Regional Officefor EuropoeR. Guidelines for measles and rubella outbreak investigation and response in the WHO European Region; 2013. Available from: https:/www.euro.who.int/en/health-topics/communicable-diseases/measles-and-rubella/publications/2013/ guidelines-for-measles-and-rubella-outbreak-investigation-and-response-in-the-who-european-region. Accessed February 3, 2022.

17. Maryland Department of Health and Mental Hygiene; Prevention and Health Promotion Administration; Infectious Disease Epidemiology and Outbreak Response Bureau (IDEORB); Center for Immunization Local health department guidelines for the epidemiological investigation and control of measles; 2017. Available from: https://health.maryland.gov/phpa/IDEHASharedDocuments/Measles\%20Investigation\%20Guidelines\% 20final.pdf. Accessed February 3, 2022.

18. World Health Organization; Regional Office for the Western Pacific. Measles elimination field guide. Available from: https://apps.who.int/iris/ handle/10665/207664. Accessed January 21, 2022.

19. Nelson AR. Coordinated effort needed to improve health care quality. QA Rev. 1989;1(5):1-6.

20. Ahmed Z, Saeed A, Ahmed E, et al. Measles outbreak investigation in nomadic population Nasirabad, Balochistan, Pakistan February 2018. Global Biosecurity. 2020;1:4.

21. Rabiu M, Mohammed RA, Liman B, Alayande A, Obinna O, Ibrahim D. Report of measles outbreak investigation in Dan Manau community of Bakura LGA, Zamfara State, Northwest Nigeria. Med Res Chronicles. 2020;7(3):155-162.

22. Siddalingaiah HS, Chaudhuri A, Chandrakala D. Measles occurrence, vaccination coverages and malnutrition in India: correlations, trends, and projections by time series analysis. Int J Community Med. 2018;5(1):86-94.

23. W/Kidan F, Getachew D, Mekonnen B, Hammeso WW. Risk factors of measles outbreak among students of Mizan-Tepi University, Tepi Campus, Southwest Ethiopia. Infect Drug Resist. 2021;14:963-970. doi:10.2147/IDR.S296928

24. Kalil FS, Gemeda DH, Bedaso MH, Wario SK. Measles outbreak investigation in Ginnir district of Bale zone, Oromia region, Southeast Ethiopia, May 2019. Pan Afr Med J. 2020;36:20. doi:10.11604/pamj.2020.36.20.21169

25. Ayele WM. Malnutrition precipitated measles outbreak in Gewane District, Afar Regional State, Northeastern Ethiopia, 2016 [Pre-print; 2016$].$ Available from: https://www.researchgate.net/publication/341841064_Malnutrition_Precipitated_Measles_Outbreak_in_Gewane_District_Afar_ Regional_State_Northeastern_Ethiopia_2016. Accessed February 3, 2022. doi:10.21203/rs.3.rs-32423/v1 
26. Menke A, Rex-Haffner M, Klengel T, Binder EB, Mehta. Peripheral blood gene expression: it all boils down to the RNA collection tubes. BMC Res Notes. 2012;5(1):1. doi:10.1186/1756-0500-5-1

27. Shehu UL, Nguku P, Hamza A. Outbreak investigation report of measles among children under five years in Katsina State, Northern Nigeria, January 2013. Int J Infect Dis. 2014;21(Suppl 1):35. doi:10.1016/j.ijid.2014.03.487

28. Bekele BB, Legese T, Daniel A, Kumalo A, Yiman H, Lamaro T. Determinants of measles recurrent outbreak in South West Ethiopia: an obstacle for implementation of infectious disease eradication in the country. EC Microbiol. 2018;14(10):699-706.

29. Coronado F, Musa N, Ahmed El Tayeb ES, et al. Retrospective measles outbreak investigation: Sudan, 2004. J Trop Pediatr. 2006;52(5):329-334. doi:10.1093/tropej/fml026

30. Mulholland K, Kretsinger K, Wondwossen L, Crowcroft N. Action needed now to prevent further increases in measles and measles deaths in the coming years. Lancet. 2020;396(10265):1782-1784. doi:10.1016/S0140-6736(20)32394-1

31. Girmay A, Dadi AF. Being unvaccinated and having a contact history increased the risk of measles infection during an outbreak: a finding from measles outbreak investigation in rural district of Ethiopia. BMC Infect Dis. 2019;19:345. doi:10.1186/s12879-019-3973-8

32. Gupta SN, Vidya R, Gupta N, Gupte MD. Factors precipitating outbreaks of measles in district Kangra of North India: a case-control study. Int J Appl Basic Med Res. 2011;1(1):24-30. doi:10.4103/2229-516X.81976

33. Majwala RK, Nakiire L, Kadobera D, et al. Measles outbreak propagated by children congregating at water collection points in Mayuge District, eastern Uganda, July - October, 2016. BMC Infect Dis. 2018;18(1):412. doi: 10.1186/s12879-018-3304-5.

34. World Health Organization. WHO guidelines for epidemic preparedness and response to measles outbreaks; 1999. Available from: https://apps.who. int/iris/bitstream/handle/10665/66034/WHO_CDS_CSR_ISR_99.1.pdf. Accessed February 3, 2022.

35. Food and Nutrition Technical Assistance III Project (FANTA_- Nutrition Assessment, Counseling, and Support (NACS): A User's Guide-_Module 2: Nutrition Assessment and Classification, Version 2; 2016. Available from: https://www.fantaproject.org/sites/default/files/resources/NACSUsers-Guide-Module2-May2016.pdf. Accessed February 3, 2022.

36. The World Bank. MEASURE DHS: Demographic and Health Surveys. Ethiopian Demographic and Health Survey EDHS; 2016. Available from: https://microdata.worldbank.org/index.php/catalog/dhs. Accessed February 22, 2022.

37. The Food and Nutrition Technical Assistance III Project . How to calculate weight-for-height Z-score (WHZ) in children 0-59 months of Age.:6-9; 2016. Available from: https://www.fantaproject.org/sites/default/files/download/Calculate-WHZ-2.6-NACS-Users-Guide-Apr2016.pdf. Accessed February 3, 2022.

38. Tariku MK, Misikir SW. Measles outbreak investigation in Artuma Fursi Woreda, Oromia Zone, Amhara Region, Ethiopia, 2018: a case control study. BMC Res Notes. 2019;12(1):765. doi:10.1186/s13104-019-4806-y

39. Joshi AB, Luman ET, Nandy R, Subedi BK, Liyanage BL, Wierzba TF. Measles deaths in Nepal: estimating the national case - fatality ratio. Bull WHO. 2009;87(6):456-465. doi:10.2471/blt.07.050427

40. Dzeyie KA, Lowang D, Dikid T, Wangsu W, Tamir T, Working Group. Measles outbreak investigation at Indo-Myanmar border, Longding District, Arunachal Pradesh, India, 2017. Indian J Public Health. 2021;65(Supplement):S23-S28. doi: 10.4103/ijph.IJPH_1067_20

41. World Health Organization. Planning and implementing high-quality supplementary immunization activities for injectable vaccines using an example of measles and rubella vaccines field guide; 2016. Available from: https:/www.who.int/publications/i/item/9789241511254. Accessed February 3, 2022.

42. Gavi, Independent Review Committee. Report of the new proposal independent review committee to the gavi alliance secretariat on the review of applications; July 2018. Available from: https:/www.gavi.org/sites/default/files/sites/default/files/document/irc-reports/Final\%20report\%20for\% 20IRC\%20July\%202018.pdf. Accessed February 22, 2022.

43. Médecins Sans Frontières. Resurgence of measles outbreaks: the need for appropriate and timely response; 2012. Available from: https://www.msf. org/sites/msf.org/files/2018-08/resurgence-of-measles-outbreaks.pdf. Accessed February 3, 2022.

44. Nujum ZT, Varghese S. Investigation of an outbreak of measles: failure to vaccinate or vaccine failure in a community of predominantly fishermen in Kerala. J Infect Public Health. 2015;8(1):11-19. doi:10.1016/j.jiph.2014.07.013

45. Zahoor MA, Rasool MH, Waseem M, et al. Prevalence of measles in vaccinated and non-vaccinated children. EXCLI J. 2015;14:504-507. doi:10.17179/excli2015-170

46. Babalola OJ, Ibrahim IN, Kusfa IU, et al. Measles outbreak investigation in an urban slum of Kaduna Metropolis, Kaduna State, Nigeria, March 2015. Pan Afr Med J. 2019;32:150. doi:10.11604/pamj.2019.32.150.15764

47. Mishra A, Mishra S, Lahariya C. Under nutrition and measles related complications in an outbreak of measles. Indian J Public Health. 2008;52 (4):221-223

48. Gignoux E, Polonsky J, Ciglenecki I, et al. Risk factors for measles mortality and the importance of decentralized case management during an unusually large measles epidemic in eastern Democratic Republic of Congo in 2013. PloS One. 2018;13:1-12.

49. Tsegaye G, Gezahagn Y, Bedada S, Berhanu N, Gudina G, Mulatu G. Epidemiology of Measles in Bale Zone, Southeast Ethiopia: analysis of surveillance data from 2013 to 2019. Risk Manag Healthc Policy. 2021;14:4093-4103. doi:10.2147/RMHP.S325173

Infection and Drug Resistance

Dovepress

\section{Publish your work in this journal}

Infection and Drug Resistance is an international, peer-reviewed open-access journal that focuses on the optimal treatment of infection (bacterial, fungal and viral) and the development and institution of preventive strategies to minimize the development and spread of resistance. The journal is specifically concerned with the epidemiology of antibiotic resistance and the mechanisms of resistance development and diffusion in both hospitals and the community. The manuscript management system is completely online and includes a very quick and fair peer-review system, which is all easy to use. Visit http://www.dovepress.com/testimonials.php to read real quotes from published authors.

Submit your manuscript here: https://www.dovepress.com/infection-and-drug-resistance-journal 